\title{
The Intelligent Temperature Control System Based on Greenhouse
}

\author{
Ziying Sun \\ School of North China Electric Power University, Baoding 071000, China. \\ szy96730@163.com
}

\begin{abstract}
In this paper, we introduce a intelligent temperature control system based on greenhouse. The system include two automatic induction device,which can feel the temperature changes; a solar-thermal heating system with electrical heating auxiliary,that the most important in the system;a tubular lamp for plant growing,which powered by solar panels ,besides we also set several wind windows to make the temperature decrease.By these measures, we not only can keep the plants grow under the best condition to increase the crop yields, but also can help us to save more energy by the way of use the solar panels.
\end{abstract}

Keywords: Greenhouse .Intelligent temperature control,save energy,environment friendly

\section{Backgrounds}

Under the influence of constructing “The world modern garden “,all kinds of agricultural greenhouse have sprung up rapidly and it's radiation begun to take shape,providing good conditions for people's material and cultural life in order to speed up the development of greenhouse sound and fast at high level and improve the production and quality of agricultural products in greenhouse. The greenhouses'construction need to introduce technologies to upgrade ,making its more intelligent and automatic.In the face of diverse needs from broad masses and the rapid growth of population,we got more reasons to introduce new technologies to upgrade the construction of greenhouse.

\section{Introduction}

Compared with traditional greenhouse, this system can auto sensing the temperature's variation and take relevant countermeasures to keep the plant stay in the optimal growth condition.

when the sensors feel the temperature is too low ,the sensors will send the signal to the solar-thermal heating system with electrical heating auxiliary equipment,hot cycling water then flows to the anti-corrosive pipeline which are laided in soils.In this process ,the hot water will transfer the heat to the soil, and then the air can be heated. So in this way ,we can manage the temperature of the greenhouse and avoid the roots of the plants got frostbite. This small system concludes antifreeze circulation and undergrounds water circulation.In order to make it more 
efficient we choose ethylene glycol as cycle liquid,when lighting is adequate,ethylene glycol will be heated ,then this cycling liquid will flow past the high-efficiency inned tube heat exchanger to heat the cycling water.

The reason why we lasid the pipeline in the soil because a research found that if the temperature of the soil change $1^{\circ} \mathrm{C}$, the growth of the plants will change obviously ${ }^{[3]}$. The effect of the soil's temperature is various ${ }^{[1,2]}$,it can influence the growth model, dry matter production and root cap ratio of the plants.It's the most important living conditions to the plants.

Except the way noted earlier ,the tubular lamp which are setted on the top of the greenhouse also can play an important role in temperature's control.In addition when in overcast and cold winter,the sun's light will decrease, and the plants will have fewer hours of sunlight,if we take advantage of this small system we not only can transform the luminous energy,which come from the lamp, into thermal energy ,but also can longer the daytime of plants and help them get the best light intensity.By the way the tubular lamps are powered by solar energy,so we don't have to worry about the energy usage.The solar panels will store the electrical energy in sunny day and discharging in overcast and the twilight of winter.

The last but not the least ,helping the greenhouse to decrease temperature is equal to warm-up the greenhouse .If the temperature goes too high,some thermolabile plants will stop growing .To avoid this phenomenon,we also design two wind windows on the both sides of the greenhouse and two wind windows on the top of the greenhouse. When the sensors feel the temperature is too high ,the wind windows will open up by themselves .So this small system can help us to prevent the temperature goes too high and keep the temperature stay in a optimal range.

\section{Structure of the system}

The optical sensor and temperature sensor will feel the change of light and temperature.If the sunlight up to the standard ,that has been set before ,but if the temperature doesn't reach to the best growing conditions the hot water from solar-thermal heating system with electrical heating auxiliary is going to cycle. If the light is insufficient and the temperature is too low the tubular lamp will light up and the hot water will begin to cycle.Another situation is the temperature is too high.In order to solve this the wind window will open up to decrease the temperature.

At the same time, the optical sensor can timing ,we can set the best illumination time.If the illumination time doesn't meet to our requirement ,the lamps will light up until the plants get enough illumination time. By the way ,all temperature control function can be start by human,no matter what environment they stay,and the number of the opened wind window can be manually set. 


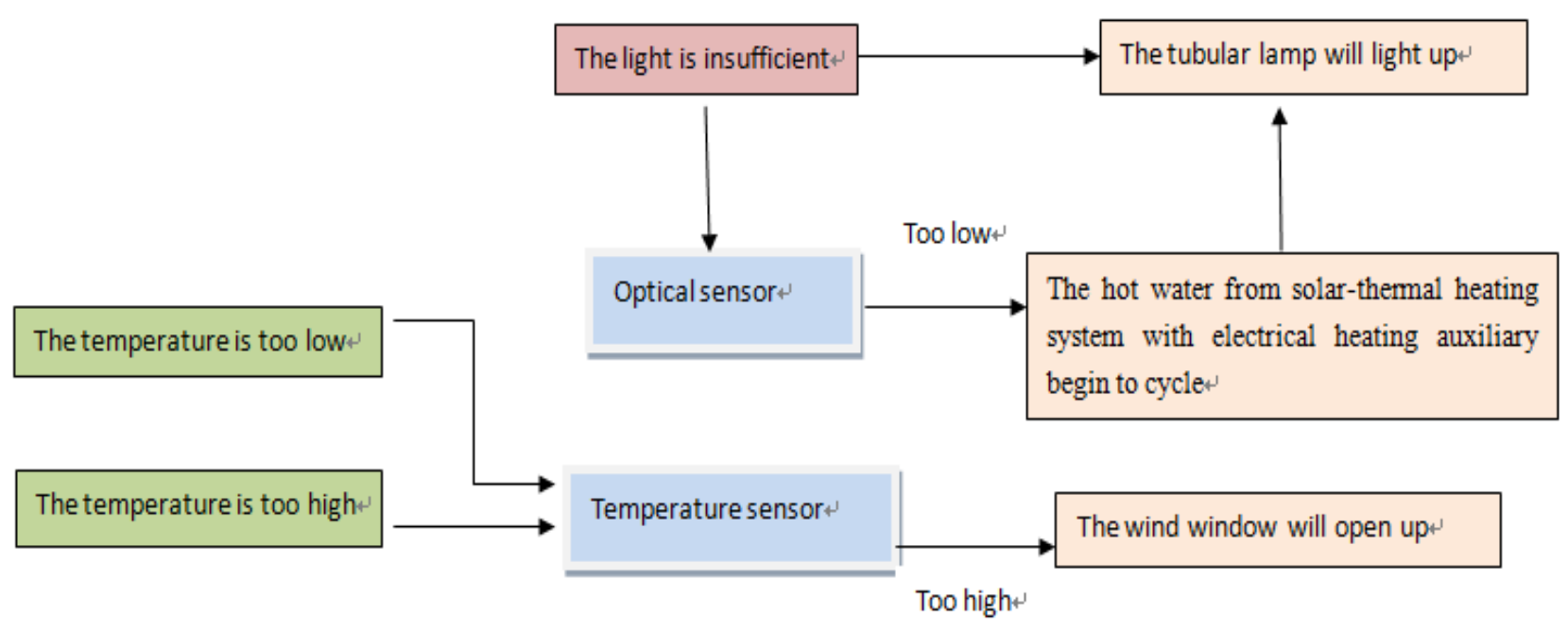

Fig. 1 Progress of the System

\section{Design}

\subsection{Structure of the Greenhouse}

Outside the greenhouse we set a storage tank with a solar energy vacuumed collecting-heat tubes.The exchanger will be heated and pass through a series of metal tubes then arrive in the storage tank to heat the water.Meanwhile we also set two pumps, one of them will pumping the hot water into the anti-corrosive pipeline to heat the soil,the other one will help the water back into the storage tank.

In the green house we set two automatic induction device to feel the change of light and temperature . We set tubular lamp for plant growing on the top to help the plants get enough light and help the temperature stay in the best condition.It is worth mentioning that all of them are power by solar panels.

We design some wind windows on the both side and the top of the greenhouse.

\subsection{Solar-thermal Heating System With Electrical Heating Auxiliary}

This system is most important to the temperature control ,because it not just to make the temperature goes high and it can help us to heat the soil,which I value so much and play the most important role to the plants' growth,it is divided into antifreeze circulation and underground water circulation. We regard ethylene glycol antifreeze as heating medium, with a low melting point and is difficult to freeze. It is also not easy to frost crack pipes even below $0^{\circ} \mathrm{C}$ outside. The hot antifreeze is then sent to the water storage tank to heat cycling water. In order to let water flow through water tank in the form of turbulent flow, baffles are installed, which can slow down cold water and improve the efficiency of heat transferring. The radius of the U-shaped finned tube heat exchanger is more than $10 \mathrm{~mm}$, so the transfer area is larger. At the same time, the material of the exchanger is brass, which has a higher heat transfer coefficient. When water flow through the mixer, temperature measuring device can adjust the proportion of hot and cold water by virtue of standard temperature. 


\subsection{Lamp For Plants Growing System}

We set them on the top of the greenhouse , the feel of the sensors will decide when the lamps are going to work.

\subsection{Wind Window system}

It can be opened by human or by the feel of the temperature sensor,to help the high temperature go down.

\subsection{To express the system more intuitively, we draw them by CAD:}

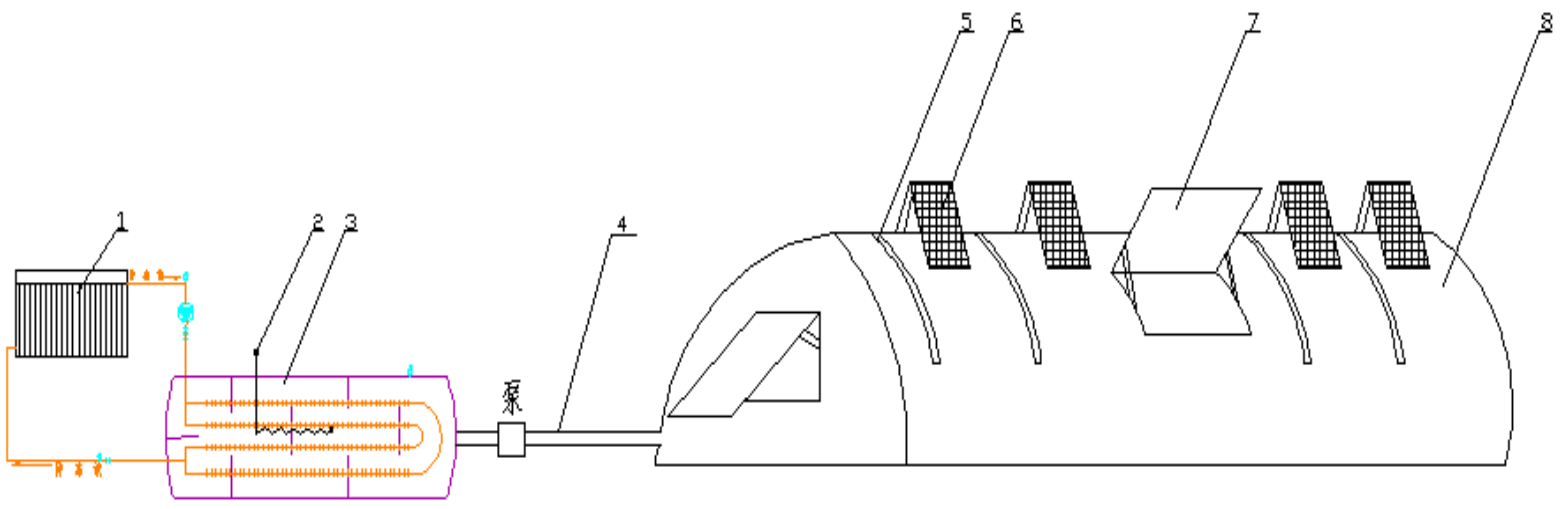

Fig. 2 The Structure of the greenhouse

1:Solar vacuum tube panels; 2:Electrical heater; 3:Water tank; 4:anti-corrosive pipeline;5:tubular lamp for plants growing;6:solar panels;7:windwinow;8:the green house
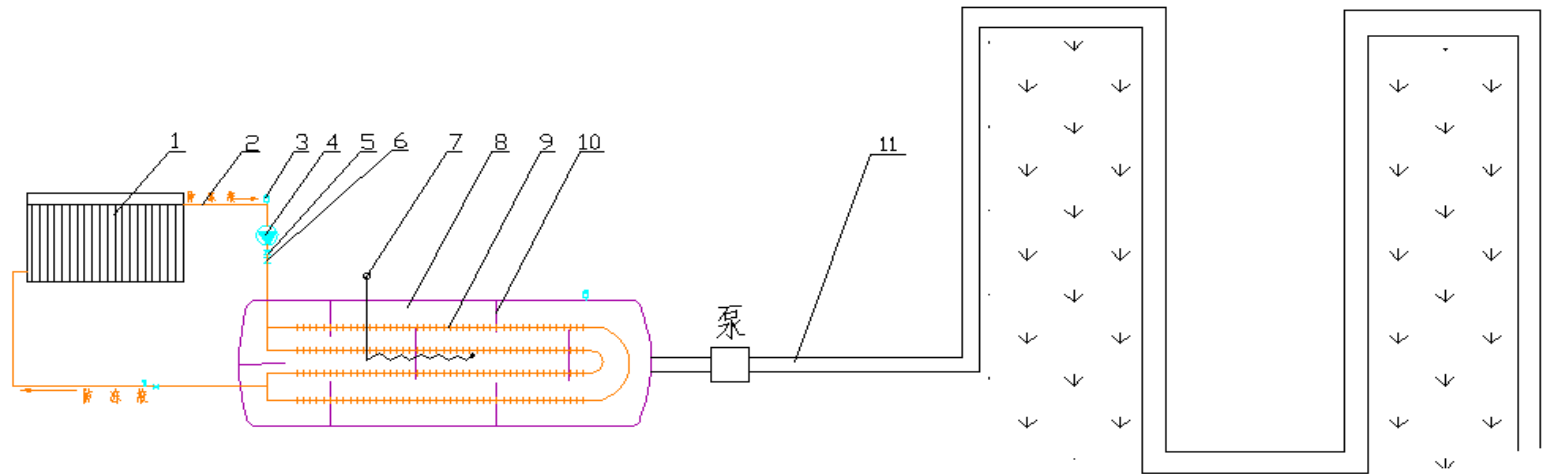

Fig. 3. Solar-thermal Heating System With Electrical Heating Auxiliary and water cycle

1:Solar vacuum tube panels; 2:Antifreeze pipe; 3: Vent valve; 4:Pump; 5: Check valve; 6: Butterfly damper; 7:Electrical heater; 8:Water tank; 9: Finned tube heat exchanger; 10:Baffle;11:anti-corrosive pipeline

\section{Conclusions}

With the agricultural economy developing and the increasing process of population,the structure of the agriculture have to constantly adjust to the current situation.The facilities of agricultural production,especially that,the way to take the advantage of greenhouse to produce developing rapidly.The greenhouse not only can take full advantage to climatic resource,but also can dynamicly 
increase the yield and quality of the crop,meanwhile the economic benefit can appear. ${ }^{[4]}$

However,the temperature is the most important factor to the plants ,it is the basis factor to help plants grow well.So in order to control the temperature I design this system.I hope this system can be very helpful.

In the future I hope we can improve the agricultural automation level and the work efficiency of the farmer.In a word ,I hope the technological development can make our life better.

\section{References}

[1]YuLong Feng,EnJu Liu,GuoBin Sun.The Influence Of The Root's Temperature .I-The Root's Temperature Affects The Photosynthesis Of The Plants.Learning newspaper of NEFU.1995,23(3):63-39.

[2] YuLong Feng,EnJu Liu,GuoBin Sun.The Influence Of The Root's Temperature.II-The Root's Temperature Affects The Metabolism Of The Plants.Learning newspaper of NEFU.1995,23(3):63-39

[3]Walker JM. One-Degree Increment in Soil Temperature Affects Maize Seedling Behavior.Soc.Sol Sci,Amer 1969,33:729-736.

[4]XiaoMei Wu,JinMing Bao,LiSheng Cui.The Use of Rockwell PlC In Ten Floor Elevator Control System 